\title{
HVMANITAS
}

\section{Sócrates y el amor según Máximo de Tiro}
Autor(es):
Martínez Hernández, Marcos

Publicado por: Imprensa da Universidade de Coimbra

URL persistente:

URI:http://hdl.handle.net/10316.2/27383

DOI:

DOI:http://dx.doi.org/10.14195/2183-1718_64_5

Accessed : $\quad$ 26-Apr-2023 04:33:25

A navegação consulta e descarregamento dos títulos inseridos nas Bibliotecas Digitais UC Digitalis, UC Pombalina e UC Impactum, pressupõem a aceitação plena e sem reservas dos Termos e Condições de Uso destas Bibliotecas Digitais, disponíveis em https://digitalis.uc.pt/pt-pt/termos.

Conforme exposto nos referidos Termos e Condições de Uso, o descarregamento de títulos de acesso restrito requer uma licença válida de autorização devendo o utilizador aceder ao(s) documento(s) a partir de um endereço de IP da instituição detentora da supramencionada licença.

Ao utilizador é apenas permitido o descarregamento para uso pessoal, pelo que o emprego do(s) título(s) descarregado(s) para outro fim, designadamente comercial, carece de autorização do respetivo autor ou editor da obra.

Na medida em que todas as obras da UC Digitalis se encontram protegidas pelo Código do Direito de Autor e Direitos Conexos e demais legislação aplicável, toda a cópia, parcial ou total, deste documento, nos casos em que é legalmente admitida, deverá conter ou fazer-se acompanhar por este aviso.

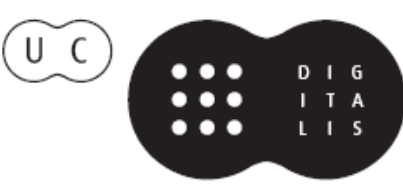


humanitas

\section{Vol. LXIV \\ 2012}

IMPRENSA DA UNIVERSIDADE DE COIMBRA

COIMBRA UNIVERSITY PRESS 


\title{
SÓCRATES Y EL AMOR SEGÚN MÁXIMO DE TIRO
}

\author{
Marcos Martínez Hernández \\ Universidad Complutense de Madrid
}

\section{Resumen}

En el presente artículo se aborda la especial relación de Sócrates con el amor (especialmente homoerótico) tal como lo comenta el fenicio Máximo de Tiro (s. II d. C.) en cuatro de sus Disertaciones (18-21) que tienen como título la erótica de Sócrates.

Palabras clave: Sócrates, amor, erótica socrática, Máximo de Tiro.

\begin{abstract}
The article focuses on the special relationship Socrates establishes with (mainly homoerotic) love, as stated by the Greek rhetorician Maximus of Tyre (2ndc AD) in four of his Dissertations (18-21), entitled Socrates' eroticism.

Key words: Socrates, love, socratic eroticism, Maximus Tyrios

1. En este artículo pretendo abordar un tema -dentro de una línea de investigación sobre literatura erótica griega que se remonta a los años ochenta del siglo pasado- hasta cierto punto delicado, como es todo lo relacionado con Sócrates y el amor y su técnica amorosa, objeto de muchos debates y comentarios desde la propia antigüedad. Mi aportación tendrá dos partes claramente diferenciadas, siendo la primera exponer lo que concierne a Sócrates y su técnica erótica tal como se describe en las fuentes griegas que hablan de ella, para ceñirme en la segunda a comentar la visión que sobre el mismo tema tiene Máximo de Tiro. Estamos de acuerdo con muchos estudiosos cuando califican a Sócrates como el primer individuo surgido en
\end{abstract}


la historia del pensamiento occidental, cuya personalidad es incomparable, original y única, o sea, un personaje irrepetible que ha ejercido una influencia universal sobre el conjunto de la tradición occidental (P. Hadot, 2006: 79). Ahora bien, lo que sabemos de Sócrates no nos ha llegado por él mismo, que, como todos sabemos, no escribió nada. El retrato que tenemos del gran filósofo ateniense nos ha llegado por los Diálogos de Platón, donde su presencia es abrumadora, sólo está ausente en Las Leyes, y ciertas obras de Jenofonte (Recuerdos, Banquete y Apología, entre otras), así como extensas referencias en las obras de Esquines, Diógenes Laercio (II, 18-47) y Ateneo de Náucratis (V,215c-221a), especialmente. Los testimonios de la comedia, como Las Nubes de Aristófanes, hay que tomarlos con mucha cautela precisamente por su contenido paródico. En consecuencia, siempre se nos plantea la duda, en el caso de Sócrates, de si lo que ponen en su boca los autores citados corresponde al Sócrates histórico o es producto e invención de los escritores que lo citan. De ahí que un estudioso cualificado como Ch. Kahn concluya recientemente que "el problema del Sócrates histórico no sólo es controvertible, sino quizás insoluble" (Kahn, 2010: 96). De todas maneras, en el caso de Platón, no hay una discrepancia fundamental entre la filosofía de Sócrates y la suya propia. Para lo más importante sobre la figura del Sócrates histórico y el tema que nos ocupa remitimos a las páginas de R. O. Moscone (2010: 31-73), Ch. Kahn (2010: 95-122), K. J. Dover (2008: 231-254) y P. Hadot (2006: 79 - 107).

2. Para entender mucho de lo que luego vamos a decir conviene que abordemos cuanto antes el concepto griego de paiderastía, trascrito al castellano como pederastia, que al decir de uno de sus mejores estudiosos "ha sido en diversos sentidos un problema filológico durante bastante tiempo y sólo ahora puede decirse que estamos asistiendo a una clarificación del tema" (M. Brioso, 1999: 7). Para comprender estas palabras del afamado helenista sevillano basta con comparar las definiciones que de este concepto se hacen en el Diccionario de la lengua española de la Real Academia (“abuso sexual cometido con niños", $22^{\mathrm{a}}$ edición, 2011, p. 1160) y la que podemos leer en modernos diccionarios de erotismo, como el de F. Rodríguez González (2011: 773): "En la Antigüedad, sobre todo en la Grecia antigua, relación sexual y pedagógica que mantiene un hombre adulto con un joven adolescente, generalmente dentro de un ritual y unas convenciones socialmente admitidas". Ese mismo diccionario reconoce que el sentido que le da el diccionario de la Real Academia es el uso que el 
término tiene hoy normalmente, pero lo distingue, como debe ser, del de homosexualidad y pedofilia, aunque se relaciona con otros más o menos sinónimos como el de amor dorio (p. 76) o amor socrático (p. 81). Estas distinciones quedan muy bien explicadas en el Diccionario editado por R. Moreno (2011:33): "La primera matización que debe hacerse al estudiar las relaciones amorosas entre hombres en la antigüedad clásica consiste en desvincularlas del concepto de homosexualidad tal como se entiende en la actualidad: las relaciones homosexuales que se consideraban lícitas era aquellas en las que un varón adulto (erastés) seducía a un joven (erómenos), que asumía un papel pasivo en todos los niveles". La pederastia entendida así tuvo mucha importancia en la paideia de la Grecia antigua y tuvo su apogeo en los siglos VI y V a. C., siendo Sócrates uno de sus máximos impulsores, para quien el vínculo especial que se establecía entre un adolescente y un adulto que lo formaba era sinónimo de amor: el adulto aportaba sus conocimientos y experiencias; el joven, la candidez, la espontaneidad y la belleza, estando el amor entre ambos unido a la sabiduría y al avance espiritual (G. Morales, 2006: 194). Este amor de los muchachos estuvo en franca competencia con el amor heterosexual durante siglos y sólo en los primeros siglos de nuestra era perdió cierta actualidad e intensidad, como ha explicado muy bien M. Brioso (2000) en su estudio sobre el debate de estos dos tipos de amores en la literatura imperial. Por lo demás, la historia de la pederastia en la Grecia antigua la ha hecho muy brillantemente hace ya algunos años F. Buffière (1980), mientras que para la homosexualidad griega sigue siendo imprescindible el libro de K. J. Dover (2008, original de 1978).

3. Dicho lo anterior sobre la pederastia en sentido griego del concepto debemos abordar ahora, antes de entrar propiamente en la erótica socrática, otra cuestión que creemos importante a la hora de enfrentarse con cualquier aspecto de los asuntos del amor de un hombre griego antiguo: la bisexualidad. ¿Eran bisexuales los griegos de la antigüiedad? Nadie mejor que M. Foucault (1987, vol. 2: 173) ha contestado a esta pregunta: "Si se quiere decir por ello que un griego podía, simultáneamente o uno tras otro, amar a un muchacho y a una muchacha, que un hombre casado podía tener sus paidiká (amados), que era común que tras inclinaciones de juventud se propendiera más bien a las mujeres, puede decirse efectivamente que eran bisexuales". Estas palabras cuadran muy bien con la figura del Sócrates histórico tal como nos lo describen las fuentes originales. Curiosamente 
sobre la sexualidad de Sócrates guarda silencio Aristófanes en Las Nubes, donde, por lo demás, lo critica en otros muchos aspectos. Noticias aisladas, como la de Aristóxeno, nos hablan de una fuerte tendencia heterosexual de nuestro filósofo (Dover, 2008: 231). Pero el ambiente en el que se desenvuelve en las obras de Platón y Jenofonte es marcadamente homosexual: muchos jóvenes amigos de Sócrates están normalmente enamorados de muchachos (Ctesipo y Clinias, Hipotales y Lisis, etc.). Al mismo Sócrates se le conocen más de cuarenta relaciones masculinas, especialmente cariñosas (Antístenes, Aristodemo, Critón, Critóbulo, Fedro, Cármides, etc.), pero cuatro de ellas se piensa que fueron sus grandes amores masculinos: Arquelao, Querefonte, Alcibíades y Platón, todos ellos jóvenes, bellos, nobles y ricos (Moscone, 2010: 93-112 y 117-177). Pero, por otra parte, nuestro filósofo estuvo casado con Jantipa, con la que tuvo tres hijos (Lamprocles, Sofronisco y Menéxeno) y es muy debatido un segundo matrimonio con una tal Mirto, por lo que se llegó a insinuar que Sócrates era un "mujeriego" (Calero Secall, 2003: 33 y 54). Pero mejor que este calificativo me parece el que le aplica R. O. Moscone (2011: 115): Sócrates era erotikós en el sentido de "persona a la que le domina el deseo de ser amada". G. Steiner (2004: 33) lo califica de "erotista", entendiendo por tal que la cualidad del amor, desde la lascivia hasta la trascendencia, el despliegue del eros en lo político, en el alma individual y en la búsqueda de verdades primordiales, exigía sus indagaciones y son temas recurrentes en su pensamiento.

4. Llegados e este punto es el momento de decir algo sobre Sócrates y el amor para comprender qué es lo que se entiende por erótica socrática. A este respecto son numerosas las manifestaciones de Sócrates en los diálogos platónicos y obras de Jenofonte que alardean de un profundo conocimiento del sentimiento amoroso en nuestro protagonista. Citaremos las más importantes:

Plat. Banq. 177d.: "afirmo no saber ninguna otra cosa que los asuntos del amor", frase que inspiró el título del libro de R. O. Moscone (2010).

“ “ 198c.: "afirmé que era un experto en las cosas de amor sin saber de hecho nada del asunto" (cómo se debe hacer un encomio cualquiera). 
Plat. Teages 128b.: "Yo soy una persona que, por así decirlo, no sé nada, excepto un insignificante conocimiento, el del amor. En cambio, en este conocimiento me considero más experto que cualquiera de los antepasados y de los hombres de nuestros días".

Plat. Lisis 204b: "Negligente y torpe como soy para la mayoría de las cosas, se me ha dado, supongo, por el dios, una cierta facilidad de conocer al que ama y al que es amado".

Jenof. Recuerdos II, 2, 28: “Tal vez yo también podría ayudarte un poco en esta cacería por el hecho de que soy entendido en cosas del amor".

Luciano, Subasta de vidas, 15: "Soy pederasta y entiendo de temas del amor".

Estas manifestaciones literales que hemos citado de Sócrates como entendido y experto en los asuntos amorosos deben completarse con otras en las que clarifica explícitamente de qué tipo de amor se trata: el de los muchachos. Así, por ejemplo, en Plat. Banq. 216d manifiesta que está "en permanente disposición amorosa con los jóvenes bellos", que recuerda mucho a las palabras de Jenofonte en Banq. VIII, 2, cuando afirma que "no podría decir momento alguno en el que no esté enamorado de alguien". Ante la contemplación del hermoso Cármides el propio Sócrates confiesa que "me sentí arder y estaba fuera de mí" (Plat. Carn. 155d). En Plat. Gorg. 481d Sócrates le dice a Calicles que tiene dos amores: Alcibíades y la filosofía.

5. Entendiendo por erótica el "arte reflexionado del amor" (Foucault, 1987, vol. 2: 209) pasemos ya a decir algo de en qué consistía la erótica socrática. Para Foucault (1987, vol. 2: 213) esta erótica respondía a dar solución a la pregunta fundamental de lo que debe ser el verdadero amor o qué es el amor en su ser mismo. Lo esencial de la técnica amatoria de Sócrates consistía en perseguir insistentemente a los jóvenes y, una vez que había logrado seducirlos, los rebajaba haciéndoles sentir ignorantes a la vez que los frustraba. Luego lograba invertir las posiciones y de amante pasaba a ser amado (Moscone, 2010: 86). En esto consistía la ironía amorosa de Sócrates: fingir haberse enamorado hasta que aquel a quien ha requerido 
con sus atenciones se enamora a su vez. Esta técnica amatoria la explica perfectamente Sócrates en Jenof. Recuerdos II, 6, 28: "Porque, cuando yo deseo a alguien, me lanzo todo entero con vehemencia, a fuerza de quererles, a hacerme querer de ellos, a añorarlos para ser añorado por ellos, a desear su compañía para que ellos deseen la mía". En este sentido era un auténtico seductor: seducía a los jóvenes despertando aspiraciones que luego no satisfacía. Un ejemplo muy conocido de esta técnica lo tenemos en el Alcibíades del Banquete platónico. Por otro lado, en varias ocasiones insiste nuestro filósofo en que el amor espiritual es muy superior al carnal (Jenof. Banq. VIII, 12), por lo que el eros por la sabiduría es para Sócrates más importante y poderoso que el eros por un joven hermoso (Dover, 2008: 239). Lo dice claramente cuando afirma que "conste que no soy un amante de los cuerpos; pienso que es el alma la que realmente es bella, sin lugar a dudas" (Luciano, Subasta de vidas, 15). Hay una evidente contradicción en este arte de amar de Sócrates: no se oponía al placer amatorio corporal, pero, por otro lado, se limitaba a promover la templanza. Era lujurioso y contenido a la vez. Estaba convencido de que el dominio de sí mismo era esencial para llevar a cabo cualquier acción hermosa, siendo en este aspecto el hombre más disciplinado del mundo (Jenof. Recuerdos IV, 5, 2). Esta técnica de la contención en los asuntos amorosos se la aconsejaría Aspasia de Mileto, una famosa hetera muy relacionada con Pericles (cf. Moscone, 2010: 204 y ss; González Suárez, 1997 y Plácido Suárez, 2004). En la Cena de los eruditos de Ateneo de Náucratis (V, 219 c. y ss) se dice expresamente que Aspasia, la sabia maestra de retórica de Sócrates, a propósito de la famosa relación Sócrates-Alcibiades, ya citada, le aconseja que se contenga y llene su espíritu con la musa inspiradora con la que lo conquistará: "Infúndela en sus oídos anhelantes, que para ambos será ella comienzo de amor. Con ella lo retendrás, dirigiendo a sus orejas presentes de deseo". En este mismo pasaje de Ateneo se afirma contundentemente que "el noble Sócrates sale a al caza [amorosa] teniendo como maestro de amores a la milesia en lugar de ser él mismo cazado, como aseguraba Platón". Sócrates nos ha dejado varias definiciones de lo que entiende por amor (por ejemplo, en Plat. Fedro 237d y 238b-c y en el diálogo Lisis, donde el énfasis se pone en el concepto de philía "amistad" o el afecto que podemos sentir por un padre, un hijo, un amigo, una esposa o un amante), pero la más esencial es la que nos ofrece en el Banquete platónico que intentaremos explicar en el siguiente parágrafo. 
6. El Banquete de Platón (M. Martínez, 1986: 143-287) viene a ser una continuación de lo expuesto en el Lisis, mientras el Fedro representa una profundización de lo que se dice en el Banquete. En este diálogo, después de los discursos sobre el amor de Fedro, Pausanias, Erixímaco, Aristófanes y Agatón, Sócrates confiesa que lo que tiene que decir sobre el tema deriva de una conversación que sostuvo con la sabia sacerdotisa de Mantinea, Diotima, "la que le enseñó también las cosas del amor" (Banq. 201d). La realidad histórica de esta mujer ha sido muy cuestionada (M. Martínez, 1986: 163-164 y 2011: 281, así como Moscone, 2010: 198 y ss y Ramos Jurado, 1998) que aquí no podemos entrar a discutir. Lo importante es que la conversación Sócrates - Diotima (201d - 212a) parece contestar en orden inverso a los cinco primeros oradores y el concepto de amor que de ella resulta se está de acuerdo en que es el más cercano a los puntos de vista de Platón - Sócrates sobre la naturaleza del amor, cuyas tres notas características son que amor es todo deseo de cosas buenas y de felicidad (205d), que amor es desear que lo bueno sea de uno para siempre (206a) y que amor es procreación en la belleza, tanto corporal como espiritual (206b). Lo propio de nuestra naturaleza mortal es aspirar a ser inmortal en la media en que podamos por medio de la generación en la belleza. Este deseo de inmortalidad del hombre es producto de la naturaleza demónica o intermediaria de Eros, dios del amor, y de su genealogía, por lo que necesita de un aprendizaje que se traduce en una serie de etapas sucesivas que conduce a la contemplación de la Belleza en sí, independientemente de las bellezas particulares (M. Martínez, 1986: 155). En consecuencia, el camino del amor es como una escalera o como una ascensión de grados (Álvarez Lacruz, 2006: 21). Esta escalera del eros (del amor a los cuerpos a la contemplación de la belleza en sí) ha sido muy bien explicada recientemente en G. Reale (2004: 213-234) y L. M. Pino (1999: 98-99) y su formulación más explícita la tenemos en Banq. 211c: "pues ésta es justamente la manera correcta de acercarse a las cosas del amor o de ser conducido por otro: empezando por las cosas bellas de aquí y sirviéndose de ellas como de peldaños ir ascendiendo continuamente, en base a aquella belleza, de uno solo o dos y de dos a todos los cuerpos bellos y de los cuerpos bellos a las bellas normas de conducta, y de las normas de conducta a los bellos conocimientos, y partiendo de éstos terminar en aquel conocimiento que es conocimiento no de otra cosa, sino de aquella belleza absoluta, para que conozca al fin lo que es la belleza en sí”. En estas palabras de Diotima-Platón-Sócrates (sin que aquí nos planteemos ahora cuál de los tres es el verdadero autor) 
queda encerrado lo que hemos querido explicar hasta ahora como erótica socrática, según las fuentes originales de las que disponemos. Como colofón a esta primera parte de nuestro trabajo cabe traer a colación las palabras de H. Licht (1976: 346) como resumen del arte amatoria de nuestro filósofo: "Sócrates, como buen heleno, era sensible a la belleza juvenil masculina; la compañía íntima de los efebos le era también indispensable, pero él personalmente se abstenía en lo posible de dar prueba alguna corporal de su afecto. Era incluso capaz de renunciar a lo sensual, ya que su arte incomparable para regular las almas de los jóvenes y llevarlos a la mayor perfección ofrecía compensación suficiente".

7. Después de Platón, Jenofonte, Antístenes o Esquines, que, como hemos adelantado ya, constituyen las fuentes más antiguas de lo que venimos llamando erótica socrática, hubo toda una serie de autores que siguieron tocando los asuntos del amor, en general, y de Sócrates, en particular, en obras que tenían como título Las cosas del amor (erotiká), Sobre el amor (erotikós o perì érotos), Discursos sobre el amor (erotikoi lógoi), o bien Historias de amor, Semejanzas eróticas, Sobre la belleza, etc. Muchos de estos autores se citan en Vidas de los filósofos ilustres, de Diógenes Laercio (s. III d. C.) o en La cena de los eruditos, de Ateneo de Náucratis (ca. 200 d. C.). Sin pretender ofrecer un listado completo de los autores de este tipo de obras, ofrecemos a continuación una docena de los más importantes citados por Ateneo o Diógenes Laercio: Aristón de Ceos, Aristóteles de Estagira, Cleantes de Asos, Clearcos de Solos, Crisipo de Solos, Demetrio de Falero, Euclides de Mégara, Heraclides del Ponto, Simias de Tebas, Simón de Atenas, Teofrastro de Ereso y Zenón de Citio. Además, debemos incluir en esta relación autores como Plutarco de Queronea y su Erótico, Luciano de Samosata y sus Erotes (Amores) y, especialmente, Fovorino de Arelate y su Sobre Sócrates y su técnica erótica, obra que, desgraciadamente, sólo nos ha llegado muy fragmentariamente. Pues bien, otro de los autores que formarían parte de este grupo es nuestro Máximo de Tiro, del que vamos a hablar en los siguientes parágrafos.

8. Son pocos los datos ciertos que conocemos de Máximo de Tiro. Lo esencial lo han dicho J. L. López - J. Campos (2005: 13) en su Introducción a la traducción de sus Disertaciones filosóficas (ed. Gredos, Madrid): que era natural de Tiro, que residió en Roma en tiempos del emperador Cómodo (180-192 d. C.), que posiblemente estuvo en Éfeso y Atenas, que era un 
filósofo y conferenciante platónico y que tuvo su apogeo en el siglo segundo de nuestra era, el siglo de la llamada por Filóstrato "Segunda Sofística". En los primeros siglos de nuestra era se produce una generalización y vulgarización de la filosofía y en estos siglos de la época imperial la filosofía se preocupa más del hombre que de la ciencia, con predominio de las cuestiones éticas y morales, con lo que la obra de Máximo de Tiro se va a mover entre los ámbitos de la moralidad, la religión y la retórica. Se ha dicho que el platonismo de nuestro autor está mezclado con tesis estoicas, cínicas y socráticas, por lo que se ha calificado su pensamiento de ecléctico (F. M. Pérez Herranz, 2007: 66). De Máximo de Tiro nos han llegado cuarenta y una composiciones a las que su autor unas veces denomina lógoi (discursos), otras skémmata (investigaciones), otras philósopha zetémata (cuestiones filosóficas) y otras dialéxeis, que los traductores de Gredos citados anteriormente han traducido como Disertaciones filosóficas. La temática de estas composiciones es muy variada: el papel del filósofo en la vida, la filosofía y la poesía en general, cuestiones de ética (virtud, educación, placer, felicidad, amistad, venganza, etc.), cuestiones de física (enfermedades del cuerpo), la relación del hombre con la divinidad (sobre démones, la idea de dios en Platón, la imagen de los dioses, etc.) y muy especialmente la figura de Sócrates (el démon socrático, el juicio de Sócrates, el amor y la erótica socrática, etc.) La mecánica de elaboración de estas composiciones la ha resumido muy bien B. P. Reardon (1971: 205): se selecciona un tema bastante banal que se desarrolla siguiendo unas cuantas reglas, como no responder con un sí o un no, comenzar con referencias literarias para captar el interés, aproximarse a la materia sin presionar demasiado, multiplicar los ejemplos y paralelos sacados de la historia antigua, proporcionar citas y reminiscencias literarias para terminar con florituras y adornos que demuestren su soltura en el tema abordado. De estas cuarenta y una disertaciones cuatro se las ha agrupado bajo el epígrafe de erótica de Sócrates que en la edición de M. B. Trapp (1994) llevan los números 18 a 21 y tienen como título Cuál es la erótica de Sócrates (18), Sigue sobre el amor (19), Sigue sobre la erótica de Sócrates (20) y Sigue sobre el amor (21). Sobre estas cuatro Disertaciones hacen un buen comentario F. Buffière (1980: 543-550), M. Szarmach (1982: 63-69) y M. B. Trapp (1997: 156-186). A la dieciocho en concreto A. F. Scognamillo (1997) le ha dedicado una excelente monografía. Desgraciadamente no hemos podido consultar la Tesis de J. Puiggali (1983), que por las referencias que tenemos constituye el más exhaustivo estudio de todas las Disertaciones. 
9. En este artículo vamos a abordar sólo tres cuestiones que nos parecen muy importantes en las Disertaciones sobre Sócrates y el amor:

a) Definición de amor. Una cosa es lo que se dice y otra lo que se quiere decir (18.5). Un asunto que es doble (uno con virtud y otro con vicio) los hombres lo denominan "amor" con un solo vocablo, llamando así al dios y a la enfermedad (18.3). Para la gran mayoría "amor" es el nombre del deseo (epithymía) errabundo entre los placeres (hedonai), es un nombre común que está en disputa entre la virtud (areté) y la maldad (kakía). Para Sócrates, en cambio, es distinto al deseo, más recatado en cuanto al placer y más certero en cuanto a la virtud $(19,2 ; 20,3)$. Necesariamente el amor, si es vicio, es pasión (páthos) privada de razón (lógos), pero si es algo hermoso (kalón) es una de dos: o hay que asignarlo a la razón exenta de pasión o a la pasión entreverada de razón (20.4). En consecuencia, amor es amor de la belleza más verdadera y el que ama otra cosa que no sea la belleza ama el placer (21.4). Pero una cosa es lo bello y otra el placer. Siendo todo esto así, el amor es razón, virtud y arte (téchne), razón según la verdad, virtud según la disposición y arte según la capacidad de alcanzar lo bello. El placer es un deseo irracional (21.7). Por eso a Sócrates no le pasaba inadvertido y andaba a la caza de los cuerpos hermosos, aunque se escondieran en la palestra, en la Academia o en los banquetes y, como un hábil cazador, por medio de los cuerpos hermosos aspiraba a la verdadera belleza (21.8).

b) Insistencia en dos tipos de amor. Hay dos clases de amor: el amor puro y virtuoso y el amor impuro y vicioso. Los verdaderos amantes aman la verdadera belleza, frente a los amantes falsos que se fijan en otras cosas. Hay ejemplos históricos de ambas clases: la relación de Harmodio y Aristogitón, el famoso batallón de amantes de Epaminondas, (18, 1-2), la historia de Agesilao (19.5) y Anacreonte (20.1 y 21.1), para el primer tipo; la historia del corintio Acteón, de Periandro, tirano de Ambracia $(18,1)$, la de Paris y Jerjes $(20,7)$ y la de Darío $(21,3)$, para el segundo. A mi modo de ver, quien mejor ha descrito estas dos clases de amores es M. Foucault (1987, vol. 3: 176): "El texto de Máximo de Tiro está dedicado esencialmente -en eso consiste su tradicionalidad- a la distinción y la comparación, en unas relaciones masculinas, entre dos clases de amor: el que es 
bello y justo y el que no lo es. Esta distinción Máximo de Tiro la hace coincidir, según la tradición platónica, con la oposición entre el amor verdadero y el que no es más que su falsa apariencia. Y a partir de ahí, desarrolla la comparación sistemática y tradicional de los dos amores. Según las cualidades que les pertenecen propiamente, uno implica virtud, amistad, pudor, franqueza, estabilidad; el otro implica exceso, odio, impudor, infelicidad". Sócrates se encontró con una Grecia llena de amores perversos, amantes engañosos y jóvenes engañados. No puede intervenir para evitarlo ni con leyes ni con la fuerza, pero no ceja en su empeño de salvarlos $(19,1)$. De ahí que Sócrates actuara como un pastor que cuidaba de las criaturas descarriadas que eran los jóvenes atenienses. Por eso decía amar a todos y se anticipaba a los amantes rivales e interceptaba a los verdugos. Quiere ser el buen pastor que cuida de su rebaño y no comportarse como un ladrón $(19,2)$. No quiere ser un vendedor de remedios que imite al médico, ni un sicofanta que imite al orador, ni un sofista que imite al filósofo $(19,4$ y 20,3).

c) ¿En qué consiste, pues, la técnica erótica de Sócrates? El principio de un amor es siempre la fascinación de la belleza corporal que entra por los ojos ("los ojos son los caminos de la belleza", son el principio de todo enamoramiento). Pero para Sócrates es más importante la belleza del alma que conduce a la virtud y es independiente y libre. Por tanto, la base de un verdadero amor es la fascinación del alma, cuya belleza tiene mayor aprecio que la belleza corporal $(19,1-3)$. La técnica erótica de Sócrates consiste en disciplinar una pasión corporal sometiéndola a la razón. En esta disciplina está todo el secreto (F. Buffière, 1980: 544). En este arte Sócrates menciona como maestras suyas a Aspasia de Mileto y a Diotima de Mantinea y son sus discípulos Alcibíades, Critóbulo, Agatón, Fedro, Lisis y Cármides $(18,4)$. Es de señalar que los acusadores de Sócrates se abstuvieron de acusarlo por sus actividades amorosas $(18,6)$. La técnica amatoria (téchne erotiké) de Sócrates debe distinguir lo que es bello en verdad de lo que no lo es, pero lo aparenta, así como los amantes falsos e ilegítimos de los amantes de la belleza verdadera, al igual que los inspectores de monedas distinguen las verdaderas de las que son falsas $(18,3)$. 
10. Ahora bien, la ocupación amorosa no es exclusiva de Sócrates ni los discursos eróticos fueron un hallazgo suyo. Antes que él hubo otros autores expertos también en las cosas del amor, empezando con Homero (Kindstrand, 1973) y siguiendo con Hesiodo y Arquíloco. En este sentido Homero no es menos profesor de amor que Platón y su erótica no es inferior a la de Sócrates: véanse las relaciones de Paris - Helena, Héctor - Andrómaca, Zeus - Hera, Calipso - Odiseo, Patroclo - Aquiles, etc. $(18,8)$. Pero si hay que comparar un arte amatoria antigua con la más reciente de Sócrates Máximo de Tiro la encuentra en la hermosa Safo de Lesbos y en el sabio Anacreonte de Teos. ¿Qué otra cosa podría ser el arte de estos dos autores sino lo mismo que predicaba el arte amatoria de Sócrates? He aquí unos cuantos paralelos $(18,9)$ :

a) Ambos, Safo y Sócrates, cultivaron una peculiar amistad, la una de mujeres, el otro de varones.

b) Ambos decían amar a muchos y consumirse por todas las bellezas.

c) Lo que para Sócrates fueron Alcibiades, Cármides y Fedro, eso lo fueron para Safo Girina, Atis y Anactoria.

d) Lo que para Sócrates fueron sus rivales de profesión (Pródico, Gorgias, Trasímaco y Protágoras), eso fueron para Safo Gorgo y Andrómeda.

e) Ambos hacen uso de la ironía en el saludo de sus rivales.

f) El comportamiento de Sócrates con Alcibiades es paralelo al de Safo con Atis.

g) Ambos consideran a Eros un servidor de Afrodita.

h) Cuando Sócrates, por medio de Diotima, dice que amor florece en la prosperidad y muere en la escasez, recuerda los calificativos de Safo de amor agridulce y dador de dolores.

i) Sócrates llama al amor sofista, mientras Safo urdidor de palabras.

j) Bajo el efecto del amor, Sócrates delira por Fedro, mientras que a Safo le sacude las mientes como el viento que se abate sobre las encinas.

k) Sócrates se enfada con Jantipa cuando se lamenta por su muerte, al igual que Safo destierra el luto de su casa por la muerte de su hija.

1) El arte de Anacreonte es del mismo carácter: ama a todos los mozos hermosos; sus canciones son para la cabellera de Esmerdis, los ojos de Cleóbulo y la lozanía de Batilo, pero en ellas hay también recato; para el amor las acciones justas son hermosas; Anacreonte decía que su canción tenía encanto y sabía decir cosas encantadoras, que 
equivale a los sones de la flauta de Olimpo y de Marsias con los que compara Alcibiades a Sócrates (Plat. Banq. 215c).

Con los ejemplos de Safo y Anacreonte queda aclarada en qué consiste la erótica de Sócrates, a los ojos de nuestro autor, pasaje que ha sido objeto de una Tesis doctoral en Ottawa, cuya autora, E. Baxter (2011), se plantea la cuestión de hasta qué punto la poesía de Safo ilumina el erotismo de Sócrates y cómo las ideas de éste pueden aumentar nuestra comprensión de la imagen de Eros que la poetisa de Lesbos traza en su poesía (M. Martínez, 2004).

\section{Referencias Bibliográficas}

Álvarez Lacruz, A. (2006) El amor: de Platón a hoy, ed. Palabra, Madrid.

BAXTER, E. (2011) Sappho and Socrates and the nature of Eros, Digital Dissertation, Ottawa.

Brioso, M. (1999) "La pederastia en la novela griega antigua", Excerpta Philologica, 9, pp. 7-50.

- (2000) "El debate sobre los dos amores en la literatura imperial", en Epieikeia.

Studia Graeca in Memoriam Jesús Lens Tuero, Granada, pp. 55-73.

BufFière, F. (1980) Eros adolescent. La pédérastie dans la Grèce antique, Les Belles Lettres, París.

Calero Secall, I. (2003) Jantipa, Ediciones del Orto, Madrid.

Dover, K. J. (2008) Homosexualidad griega, ed. El Cobre, Barcelona.

Foucault, M. (1987) Historia de la sexualidad. Vol. 2: EL Uso de los placeres, vol. 3, La inquietud de sí, ed. Siglo XXI, Madrid.

GonZÁlez SuÁreZ, A. (1997) Aspasia, Ediciones del Orto, Madrid.

Hadot, P. (2006) "La figura de Sócrates", en su libro Ejercicios espirituales y filosofía antigua, ed. Siruela, Madrid, pp. 79-107.

Kahn, Ch. (2010) Platón y el diálogo socrático, ed. Escolar y Mayo, Madrid.

KindSTRAnd, J. F. (1973) Homer in der Zweiten Sophistik, Uppsala.

LASERRE, F. (1944) "Erotikoi lógoi”, en MH, 1, pp. 169-178.

Licht, H. (1976) Vida sexual de la antigua Grecia, ed. Abraxas, Madrid.

López, J. - Campos, J. (2005) Máximo de Tiro. Disertaciones filosóficas, 2 vols. ed. Gredos, Madrid. 
Martínez Hernández, M. (1986) Platón. Banquete, vol. III de Diálogos, ed. Gredos, Madrid.

- (2004) "Safo. Poesía, amor y leyenda", en J. de la Villa (ed.), Mujeres de la Antigüedad, ed. Alianza, Madrid, pp. 39-83.

- (2011) “Mujeres literatas en la Grecia antigua”, en G. Santana (ed.), Y las letras encontraron su asiento. Mujeres y literatura, Ediciones Clásicas, Madrid, pp. 261-306.

Morales, G. (2006) Por amor al deseo. Historia del erotismo, ed. Espasa, Madrid.

Moreno Soldevila, R. , ED. (2011) Diccionario de motivos amatorios en la literatura latina (siglos III a. C. II $d$. C.), Universidad de Huelva.

Moscone, R. O (2010) Sócrates: sólo sé de amor, ed. Biblioteca Nueva, Madrid.

Pérez Herranz, F. M. (2007) "En los límites de la filosofía. A propósito de las disertaciones filosóficas de Máximo de Tiro", Eikasia. Revista de Filosofía, año II, n ${ }^{\circ}$ 9, pp. 53-7.

Pino CAmpos, L. M. (1999) “Tres modelos diferentes de erotismo literario. Platón, Apolunio de Rodas y Caritón de Afrodisias”, en Fortunatae, 11, pp. 93-112.

PlÁCIDO SUÁREZ, D. (2004) “Aspasia, la otra cara de la Atenas de Pericles”, en J. de la Villa (ed.), Mujeres de la Antigüedad, ed. Alianza, Madrid, pp. 85-98.

Puiggali, J. (1983) Étude sur les Dialexeis de Maxime de Tyr, conferencien platonicien du IIe siècle, Lille.

Ramos Jurado, E. A. (1998) "Eros demónico y mujer demónica. Diotima de Mantinea", Habis, 30, pp. 79-86.

Reale, G. (2004) Eros, demonio mediador, ed. Herder, Barcelona.

REARDON, B. P. (1971) Courrants littéraires grecs de IIe et IIIe siècles après J. $C$., ed. Les Belles Lettres, París.

Rodríguez González, F. (2011) Diccionario del sexo y el erotismo, Alianza Editorial, Madrid.

Scognamillo, A. F. (1997) Massimo di Tiro. L'arte erotica di Socrate. Orazione XVIII, ed. Congedo, Galatina.

SteIner, G. (2004) Lecciones de los maestros, ed. Siruela, Madrid.

SzARMACH, M. (1982) “Erótikoi Logoi von Maximus Tyrios”, Eos, 70, pp. 61-69.

Trapp, M. B. (1994) Maximus Tyrius. Dissertationes, ed. Teubner, Leipzig.

Trapp, M. B. (1997) Maximus of Tyre. The Philosophical Orations, Oxford. 